\title{
First joint Italian-German purine club meeting "Progress in Purinergic Receptor Pharmacology and Function"
}

\author{
Francesco Caciagli ${ }^{1} \&$ Peter Illes ${ }^{2}$ \\ ${ }^{1}$ Department of Biomedical Sciences, Gabriele D'Annunzio University of Chieti, Chieti, Italy; ${ }^{2}$ Rudolf-Boehm-Institute \\ of Pharmacology and Toxicology, University of Leipzig, Leipzig, Germany
}

The first joint meeting of the Italian and German Purine Clubs took place in Chieti (Italy) between September 18-20 of this year. The scientific program was collected by the Boards of the two National Chapters headed by F. Caciagli and P. Illes, respectively. The local organization was most efficiently managed by F. Caciagli and his team at the Campus of the University of Chieti. The technical facilities of the Center of Excellence in Chieti were of very high standard including the possibility of a direct transmission of the congress events via the local television network. The small university town of Chieti was an ideal place for a congress; it is located at an easy reach from the seaside resort Pescara, in a picturesque environment of the nearby mountains of the Abbruzzo. All of us enjoyed the warm hospitality of our hosts, the nice scenery, the tasty food and the excellent wines served during the social dinner.

In accordance with the attractive surrounding of this meeting, we had a most busy program including three state-of-the-art lectures delivered by G. Burnstock (London, UK), G. Schmalzing (Aachen, Germany) and M.P. Abbracchio (Milan, Italy). G. Burnstock gave a fascinating, personal account on his discovery of ATP as a cotransmitter in the vegetative nervous system and the subsequent identification and classification of nucleotide receptors as well as their signal transduction mechanisms and the functional consequences of their activation [1]. It is hard to understand nowadays the vigorous resistance of the scientific community to approve the idea of purinergic signalling. However, as a born fighter, G. Burnstock finally accomplished to get his convictions accepted, especially after a wide range of $\mathrm{P} 2 \mathrm{X}$ and $\mathrm{P} 2 \mathrm{Y}$ receptors had been cloned during the first half of the last decade. We have been deeply impressed by his last slide, where his past and present co-workers from all over the world were enumerated resulting in a never ending list of names.

G. Schmalzing spoke about the molecular mechanisms of $\mathrm{P} 2 \mathrm{X}$ receptor assembly and function [2]. His observation that both homomeric and heteromeric $\mathrm{P} 2 \mathrm{X}$ receptors have a trimeric architecture, contrast with the pentameric (cys-loop receptors) and tetrameric (glutamate receceptors)

Correspondence to: Dr Peter Illes, Rudolf-Boehm-Institute of Pharmacology and Toxicology, University of Leipzig, Haertelstrasse 16-18, 04107, Leipzig, Germany. Tel: +49-341-9724600; Fax: +49-3419724609; E-mail: illp@medizin.uni-leipzig.de structure of other classes of ligand-gated ion channels. By the circular architecture of P2X subunits around a central axis perpendicular to the plasma membrane, each subunit is able to contribute one or several transmembrane domains to allow for the formation of the cation conducting pore. Co-immunoprecipitation experiments show that the second transmembrane domain of each subunit carries a critical determinant of a specific subunit-subunit interaction.

M.P. Abbracchio gave an account on the pathophysiological roles of $\mathrm{P} 2$ receptors in glial cells [3]. Upon mechanical stimulation or activation by other transmitters, astrocytes release ATP and respond to ATP with a propagating wave of intracellular calcium increases, allowing homotypic astrocyte-to-astrocyte communication, as well as a heterotropic signalling which also involves neurons, oligodendrocytes and microglia. Astrocytic P2 receptors mediate reactive astrogliosis, a long-term reaction which may contribute to neuroinflammation and neuronal death in neurodegenerative diseases. Hence, astrocytes are not only passive supporting elements of the CNS but also carry on an intensive dialogue with neighbouring neurons via e.g., purinergic signalling molecules.

In addition to the main lectures, about 40 oral communications were delivered and approximately the same number of posters were presented by the participants. The time reserved for each lecture and poster was amply sufficient to accommodate an intense discussion on various items of interest. In the following, we summarize a few 'highlights,' of course biased by our personal research interests and apologize for not mentioning equally important contributions because of lack of space or expertise.

F. Di Virgilio and co-workers (Ferrara) found that $\mathrm{P}_{2} \mathrm{X}_{7}$ receptors are able to modulate mitochondrial function [4]. Accordingly, sustained stimulation of $\mathrm{P}_{2} \mathrm{X}_{7}$ receptors causes a drop of the resting mitochondrial potential, a large increase in basal mitochondrial $\mathrm{Ca}^{2+}$ concentration, and probably as a consequence mitochondrial fragmentation and cell death. I. von Kügelgen and co-workers (Bonn) investigated the structural determinants of the function of $\mathrm{P}_{2} \mathrm{Y}_{1}$ and $\mathrm{P} 2 \mathrm{Y}_{12}$ receptors. They identified two disulfide bridges of which already one was sufficient for receptor function. G. Cristalli and co-workers (Camerino) synthesized new analogues of adenosine, exhibiting high potency and selectivity for the $A_{3}$ adenosine receptor in binding studies. Docking analyses of the compounds in a model of 
the human $A_{3}$ receptor were highly compatible with the binding data. C.E. Müller an co-workers (Bonn) presented compelling evidence for the existence of an adenine (P0) receptor, which appears to be unique as it shows very narrow structure-activity relationships and only accepts minor modifications of the adenine structure. Antagonists for this adenine receptor are not available. G. Reiser and co-workers (Magdeburg) stably expressed P2 $\mathrm{Y}_{1}$ and $\mathrm{P} 2 \mathrm{Y}_{2}$ receptors with a green fluorescent protein tag on their C-terminus in HEK293 cells. Then, they confirmed the ability of diadenosine polyphosphates $\left(\mathrm{Ap}_{\mathrm{n}} \mathrm{A} ; n=2-7\right)$ to promote both $\mathrm{P} 2 \mathrm{Y}_{1}$ and $\mathrm{P} 2 \mathrm{Y}_{2}$ receptor endocytosis and to increase arachidonic acid release. They concluded that these compounds may regulate physiological processes via P2Y receptor activation. P. Illes and co-workers (Leipzig) suggested that nucleotides including ATP itself have a dual effect both at native and recombinant $\mathrm{P} 2 \mathrm{X}_{3}$ receptors. At low concentrations ecto-protein kinase $\mathrm{C}$ may transfer the terminal phosphate groups of nucleotides onto consensus phosphorylation sites of the receptors and thereby increase their sensitivity towards higher agonistic concentrations of the same nucleotides.

H. Zimmermann and co-workers (Frankfurt) studied the properties of astrocyte-like progenitor cells obtained from the subventricular zone of the lateral ventricle. They proved in this cell type that the signalling pathways via extracellular nucleotides and nucleotide receptors play a role in the control of neurogenesis. F. Caciagli and coworkers (Chieti) suggested that brain cholesterol may have an essential role in CNS function such as synapse promotion [5]. They showed in addition that guanosine, which is released both from astrocytes and neurons, and exerts neuroprotective effects probably by stimulating the release of various trophic factors, also increased cholesterol efflux from these cell-types. C. Martini and co-workers (Pisa) examined in a model of rat focal cerebral ischemia ('medial cerebral artery occlusion'; MCAO) the neuroprotective effect of adenosine $\mathrm{A}_{2 \mathrm{~A}}$ receptors [6]. They demonstrated that MCAO modulated the expression of striatal $A_{2 A}$ receptors and $G$ protein pool availability, suggesting that this receptor is a promising target for neuroprotective strategies to prevent ischemic brain damage. P.A. Borea and co-workers (Ferrara) found that under hypoxic conditions adenosine up-regulates the expression of hypoxia-inducible factor-1 (HIF-1) [7]. This effect was mediated by $\mathrm{A}_{3}$ receptors, since it was inhibited by the respective small interfering RNA. H. Schlüter and coworkers (Berlin) gave an overview on dinucleotides which were demonstrated to be released from secretory granules of the human adrenal gland, platelets, endothelial cells and heart tissue, yielding physiologically relevant concentrations in human plasma. In vascular beds the action of the dinucleotides was dependent on the expression profile of the purinergic receptors on the surface of endothelial cells and vascular smooth muscle cells. M.P. Rathbone and coworkers (Hamilton, Canada) stated that the extracellular concentration of non-adenine-based purines such as guanosine is as high or even higher than that of their adeninebased counterpart, adenosine. They found that guanosine protects agains apoptosis caused by a number of stimuli in several cell-types including astrocytoma and neuroblastoma cells. Further, they confirmed the neuroprotective effect of guanosine in various in vivo CNS injury models.

There was a separate poster session organized, where the participants could carry on lively discussions on an impressive amount of presentations. Based on suggestions made by a committee, poster prizes were awarded to P. Pellegatti, S. Merighi (both Ferrara), A. El-Tayeb (Bonn), and H. Franke (Leipzig). The prizes consisted of a diploma and a certain amount of money donated in part by the publishing house Springer, being in charge of our newly established journal 'Purinergic Signalling.' It is noteworthy that the Associate Editors of 'Purinergic Signalling' have met during the congress and on suggestion of the Editor-in-Chief, G. Burnstock, decided to urge the participants to submit papers on their presentations.

In a separate session, the possibility of an application for the establishment of a Research Training Network of the European Community (EC) entitled "Pathophysiology of purinergic signalling systems" was intensively discussed. M.P. Abbracchio was assigned as a general coordinator of this concerted action. Finally, P. Illes extended his warm invitation to all participants to take part at the Second Joint Italian-German Purine Club Meeting to be organized in the autumn of 2007 in Leipzig, Germany. He admitted that it will be difficult to cope with the high social and scientific standards set by the present meeting, but promised that the German organizers will do their utmost.

\section{References}

1. Burnstock G. Introduction: P2 receptors. Curr Top Med Chem 2004; 4: 793-803.

2. Illes P, Riebeiro AJ. Molecular physiology of $\mathrm{P} 2$ receptors in the central nervous system. Eur J Pharmacol 2004; 483: 5-17.

3. Marchetti B, Abbracchio MP. To be or not to be (inflamed) - is that the question in anti-inflammatory drug therapy of neurodegenerative disorders? Trends Pharmacol Sci 2005; 26: 517-25.

4. Di Virgilio F, Chiozzi P, Ferrari D, Falzoni S et al. Nucleotide receptors: An emerging family of regulatory molecules in blood cells. Blood 2001; 97: 587-600.

5. Ciccarelli R, Ballerini P, Sabatino G et al. Involvement of astrocytes in purine-mediated reparative processes in the brain. In $\mathrm{J}$ Dev Neurosci 2001; 19: 395-414.

6. Pedata F, Gianfriddo M, Turchi D, Melani A. The protective effect of adenosine $\mathrm{A}_{2 \mathrm{~A}}$ receptor antagonism in cerebral ischemia.

7. Merighi S, Mirandola $P$, Varani $K$ et al. A glance at adenosine receptors: Novel target for antitumor therapy. Pharmacol Ther 2003; 100: $31-48$. 